\title{
Is maternal asthma a life or death issue for the baby?
}

\author{
Michael Schatz
}

Asthma is probably the most common potentially serious medical problem to complicate pregnancy. In recent national surveys in the USA, $8.4-8.8 \%$ of pregnant women reported current asthma. ${ }^{1}$ Since 1970, many published articles have suggested that women with asthma experience more complications of pregnancy than women who do not have asthma. The most commonly reported increased risks have been for pre-eclampsia, ${ }^{2-12}$ preterm birth $^{2} 568913-15$ and infants with low birth weight or intrauterine growth restriction. ${ }^{2568-10121516}$ The most severe complication of pregnancy from the infant standpoint is fetal or neonatal death. Although one study from the USA in 1970 reported a significant $80 \%$ increased risk of perinatal mortality in infants of women with asthma compared with those without asthma, ${ }^{17}$ and another study from Sweden in 1972 reported a more than doubling of neonatal mortality in infants of mothers with asthma, ${ }^{2} 11$ studies published between 1988 and 2007 did not demonstrate a significant increased risk of fetal mortality, neonatal mortality, or both (perinatal mortality) in the infants of women with asthma compared with women without asthma. $^{3} 7101516$ 18-23 Since the prevalence of perinatal mortality is fortunately low, a type 2 error due to low statistical power could explain many of these negative results. Indeed, sample sizes for women with asthma in 7 of the 11 negative studies were less than 2000. ${ }^{3} 101618-2022$ Moreover, a significant $21 \%$ increased risk of perinatal mortality was reported in the second largest cohort of women with asthma studied to date $\left(\mathrm{n}=36\right.$ 965). ${ }^{6}$

Against this background, the study by Breton et $a^{24}$ in the current issue of Thorax (see page 101) of a database cohort of 13100 pregnant women with asthma is important in shedding light on the important question: does maternal asthma confer an increased risk of the most severe fetal or infant adverse outcome of death? This large well-designed population-based study reported a $35 \%$ increased risk of perinatal mortality in the pregnancies of women

Correspondence to: Dr M Schatz, Department of Allergy, Kaiser Permanente, San Diego, CA 92111, USA; michael.x.schatz@kp.org with asthma. Moreover, this study is the first to demonstrate that this increased risk is probably mediated by an increased risk of low birthweight and preterm infants in the pregnancies of women with asthma. The study raises three major issues: (1) Is the association valid? (2) If the association is valid, what is the mechanism? (3) In light of this information, how should pregnant patients with asthma be managed so as to minimise the risk?

Regarding the validity of the association, there appear to be two issues. The first is the validity of the information captured in the database. The accuracy of exposures and outcomes is always an issue in studies using administrative computerised data. However, the computerised data used in this study have been validated with regard to both a diagnosis of asthma and birth weight and gestational age outcomes, and several databases were used to capture perinatal mortality. The second issue is whether the association identified in this study could be explained by unmeasured confounders. The main unmeasured factor that could definitely confound this relationship is maternal smoking, which has been reported to be increased in pregnant women with asthma compared with nonasthmatic women, ${ }^{6} 102526$ and which has been clearly associated with increased perinatal mortality as well as with increased prematurity and intrauterine growth restriction. ${ }^{27-32}$ Several previous negative studies have adjusted for smoking, ${ }^{15}{ }^{18} 21-23$ but the positive study from the Swedish Medical Birth Registry ${ }^{6}$ also adjusted for smoking. Thus, although adjustment for smoking in future studies would be highly desirable, smoking may not fully explain the current association. Another unmeasured potential confounder is maternal obesity, since obesity has been reported to be increased in pregnant women with asthma ${ }^{33}$ and obesity has been reported to increase the risk of intrauterine fetal death. ${ }^{34-37}$ However, an association between maternal obesity and preterm birth or low birthweight infants has not been established. ${ }^{37}$

Although confounding could contribute to the results of the study by Breton and coworkers, ${ }^{24}$ a biological association still seems likely. There are three possible types of mechanisms that could explain the increased risk of perinatal mortality in the pregnancies of women with asthma: (1) common pathogenesis factors; (2) medications used to treat asthma; and (3) uncontrolled asthma. Since prematurity and/or low birth weight seemed to mediate the relationship between asthma and perinatal mortality in the study by Breton et al, factors that could predispose to both asthma and these outcomes may be relevant. $\beta_{2}$ Adrenergic receptors are present in both airway and uterine smooth muscle, and $\beta_{2}$ adrenergic dysfunction could explain both bronchial hyper-reactivity and preterm labour. Consistent with this hypothesis, $\beta_{2}$ agonists are used to treat both asthma and preterm labour. Most relevant is that two studies demonstrated bronchial hyper-reactivity in women without asthma who developed preterm labour. ${ }^{38}$ Common pathogenesis factors between asthma and pre-eclampsia may also be relevant since (1) pre-eclampsia has been reported to be more likely to occur in pregnant women with asthma than in those without asthma in many studies (see above), including the one by Breton et al; and (2) pre-eclampsia predisposes to preterm birth, low birth weight and fetal mortality. ${ }^{40}$ Certain mediators potentially important in pre-eclampsia such as angiotensin and endothelin are also potent bronchoconstrictors. ${ }^{41}{ }^{42}$ Again, more compelling in this regard is the report of increased bronchial hyper-reactivity in women without asthma with pre-eclampsia compared with women without asthma who did not develop pre-eclampsia. ${ }^{43}$ Thus, there are data to suggest that asthma and conditions that predispose to perinatal mortality may be caused by similar pathogenesis factors, but more data are certainly required to confirm this mechanism. Moreover, this mechanism has less clearcut therapeutic implications than either a medication or uncontrolled asthma-mediated process.

Medications are frequently required to treat asthma, and thus an asthma medication effect must be considered. A recent study of women receiving asthma drugs during pregnancy did report a relationship between perinatal mortality and the use of three or more asthma medications compared with two or less asthma medications. ${ }^{15}$ However, this may have been an asthma severity effect, although associations between specific asthma medication groups or individual medications and perinatal mortality were not reported in that study. No associations have been demonstrated between maternal use of 
inhaled $\beta$ agonists or inhaled corticosteroids and pre-eclampsia, preterm birth or low birthweight infants, ${ }^{44}{ }^{49}$ although only one of these studies reported results for a component of perinatal mortality (stillbirth).$^{45}$ In contrast, oral corticosteroids have been independently associated with lower birth weight, ${ }^{48}$ pre-eclampsia ${ }^{44}$ and prematurity. ${ }^{46}$ The study by Breton et al ${ }^{24}$ did not address a potential role for oral corticosteroids in mediating the observed relationship between maternal asthma and prematurity or perinatal mortality. However, residual confounding by asthma that is more difficult to control cannot be excluded in the above studies of oral corticosteroids.

An appealing mechanism for the association reported in the study by Breton et al is uncontrolled asthma, since asthma control is the goal of therapy in all patients with asthma. Although no studies have reported the relationships between parameters of asthma control and perinatal mortality, several studies have reported relationships between markers of asthma control and preterm birth, low birth weight or intrauterine growth retardation, which the data from the study by Breton et al suggest may mediate the increased risk of perinatal mortality in the pregnancies of women with asthma. In one study, daily asthma symptoms were significantly associated with intrauterine growth restriction while symptoms less than daily were not. ${ }^{50}$ Inadequate asthma symptom control and exacerbations requiring hospitalisations were associated with an increased risk of preterm birth in infants of mothers with asthma in another study. ${ }^{51}$ Lower maternal pulmonary function in women with asthma during pregnancy has been associated with increased risks of preterm birth, low birthweight infants or intrauterine growth restriction in two studies. $^{52}{ }^{53}$ Finally, a meta-analysis has suggested that the increased risk of low birthweight infants of mothers with asthma is limited to those women who suffer asthma exacerbations during pregnancy. ${ }^{54}$ These observational data do not, of course, prove a cause and effect relationship between inadequate asthma control and these adverse perinatal outcomes or assure us that improved control will reduce the risk. However, since a randomised controlled intervention trial to identify the effect of controlled versus uncontrolled asthma on perinatal outcomes is not ethical, these observational data may be the best we can get to direct therapy.

Indeed, the most important question raised by the study of Breton et al is: What are the clinical and therapeutic implications, since it does appear that maternal asthma can be a life or death issue for the baby? The two main "take away" clinical points are: (1) appropriate surveillance and (2) optimal asthma control. Pregnancies in women with asthma need to be considered as high-risk pregnancies, with increased obstetrical surveillance for pre-eclampsia, preterm labour or delivery, intrauterine growth restriction and fetal mortality. Moreover, infants of women with asthma need to be followed for an increased risk of neonatal mortality, especially if preterm or of low birth weight. Regarding asthma control, as noted above although not proven, one would hope that optimal control of asthma during pregnancy would reduce the risk of perinatal complications including perinatal mortality. Supporting this hypothesis is the observation that the incidence of perinatal mortality, preterm birth and low birthweight infants was not increased in three relatively large prospective studies performed during the same time period as the study by Breton et al in which the asthma was actively managed by asthma specialists ${ }^{18}{ }^{20}$ or perinatologists. ${ }^{22}$ Recent guidelines have been published for the management of asthma during pregnancy that should aid clinicians in providing optimal asthma control for their pregnant patients. ${ }^{55}$

In conclusion, although more data are clearly desirable, the study by Breton et $a l^{24}$ is an important addition to the body of literature published to date indicating that we need to manage our pregnant patients with asthma with the careful surveillance and control required of a life and death clinical situation.

Competing interests: None.

Thorax 2009;64:93-95. doi:10.1136/thx.2008.105189

\section{REFERENCES}

1. Kwon HL, Belanger K, Bracken MB. Asthma prevalence among pregnant and childbearing-aged women in the United States: estimates from national health surveys. Ann Epidemiol 2003;13:317-24.

2. Bahna SL, Bjerkedal T. The course and outcome of pregnancy in women with bronchial asthma. Acta Allergologica 1972;27:397-406.

3. Stenius-Aarniala B, Piirila P, Teramo K. Asthma and pregnancy: a prospective study of 198 pregnancies. Thorax 1988;43:12-8.

4. Lehrer S, Stone J, Lapinski R, et al. Association between pregnancy-induced hypertension and asthma during pregnancy. Am J Obstet Gynecol 1993;168:1463-6.

5. Demissie K, Breckenridge MB, Rhoads GG. Infant and maternal outcomes in the pregnancies of asthmatic women. Am J Respir Crit Care Med 1998;158:1091-5.

6. Kallen B, Rydhstroem H, Aberg A. Asthma during pregnancy - a population based study. Eur J Epidemiol 2000:16:167-71

7. Wen SW, Demissie K, Liu S. Adverse outcomes in pregnancies of asthmatic women: results from a Canadian population. Ann Epidemiol 2001;11:7-12.

8. Liu S, Wen SW, Demissie K, et al. Maternal asthma and pregnancy outcomes: a retrospective cohort study. Am J Obstet Gynecol 2001:184:90-6.
9. Acs N, Puho E, Banhidy F, et al. Association between bronchial asthma in pregnancy and shorter gestational age in a population-based study. J Matern Fetal Neonatal Med 2005;18:107-12.

10. Sheiner E, Mazor M, Levy A, et al. Pregnancy outcome of asthmatic patients: a population-based study. J Matern Fetal Neonatal Med 2005:18:237-40.

11. Kallen B, Olausson PO. Use of anti-asthmatic drugs during pregnancy. 1. Maternal characteristics, pregnancy and delivery complications. Eur J Clin Pharmacol 2007;63:363-73.

12. Enriquez R, Griffin M, Carroll KN, et al. Effect of maternal asthma and asthma control on pregnancy and perinatal outcomes. J Allergy Clin Immunol 2007; 120:625-30.

13. Kelly YJ, Brabin BJ, Milligan $P$, et al. Maternal asthma premature birth, and the risk of respiratory morbidity in schoolchildren in Merseyside. Thorax 1995;50:525-30.

14. Sorensen T, Dempsey JC, Xiao R, et al. Maternal asthma and risk of preterm delivery. Ann Epidemiol 2003;13:267-72.

15. Kallen B, Olausson PO. Use of anti-asthmatic drugs during pregnancy. 2. Infant characteristics excluding congenital malformations. Eur J Clin Pharmacol 2007;63:375-81

16. Lao TT, Huengsburg M. Labour and delivery in mothers with asthma. Eur J Obstet Gynecol Reprod Biol 1990;35:183-90.

17. Gordon $\mathbf{M}$, Niswander KR, Berendes $\mathrm{H}$, et al. Fetal morbidity following potentially anoxigenic obstetric conditions. VII. Bronchial asthma. Am J Obstet Gynecol 1970;106:421-9

18. Schatz M, Zeiger RS, Hoffman CP, et al. Perinatal outcomes in the pregnancies of asthmatic women: a prospective controlled analysis. Am J Respir Crit Care Med 1995;151:1170-4.

19. Jana N, Vasishta K, Saha SC, et al. Effect of bronchial asthma on the course of pregnancy, labour and perinatal outcome. J Obstet Gynaecol 1995;21:227-3.

20. Stenius-Aarniala BSM, Hedman J, Teramo KA. Acute asthma during pregnancy. Thorax 1996:51:411-4.

21. Demissie K, Marcella SW, Breckenridge MB, et al. Maternal asthma and transient tachypnea of the newborn. Pediatrics 1998;102:84-90.

22. Dombrowski MP, Schatz M, Wise R, et al. Asthma during pregnancy. Obstet Gynecol 2004;103:5-12.

23. Tata LJ, Lewis SA, McKeever TM, et al. A comprehensive analysis of adverse obstetric and pediatric complications in women with asthma. Am J Respir Crit Care Med 2007;175:991-7.

24. Breton $\mathbf{M}-\mathbf{C}$, Beauchesne $M-F$, Lemière $\mathbf{C}$, et al. Risk of perinatal mortality associated with asthma during pregnancy. Thorax 2009;64:101-6.

25. Dombrowski MP, Bottoms SF, Boike GM, et al. Incidence of preeclampsia among asthmatic patients lower with theophylline. Am J Obstet Gynecol 1986;155:265-7.

26. Mihrshahi S, Belousova E, Marks GB, et al. Pregnancy and birth outcomes in families with asthma. J Asthma 2003:40:181-7.

27. Shah NR, Bracken MB. A systemic review and metaanalysis of prospective studies on the association between maternal cigarette smoking and preterm deliveries. Am J Obstet Gynecol 2000;182:465-72.

28. Pollack H, Lantz PM, Frohna JG. Maternal smoking and adverse outcomes among singletons and twins. Am J Public Health 2000;90:395-400.

29. Wisborg K, Kesmodel U, Henriksen TB, et al. Exposure to tobacco smoke in utero and the risk of stillbirth and death in the first year of life. Am J Epidemiol 2001;154:322-7.

30. Magee BD, Hattis D, kivel NM. Role of smoking in low birth weight. J Reprod Med 2004:49:23-7.

31. Salihu HM, Wilson RE. Epidemiology of prenatal smoking and perinatal outcomes. Early Hum Dev 2007; 63:713-20.

32. Okah FA, Cai J, Hoff GL. Term-gestation low birth weight and health-compromising behaviors during pregnancy. Obstet Gynecol 2005;105:543-50.

33. Hendler I, Schatz M, Momirova V, et al. Association of obesity with pulmonary complications of pregnancy in asthmatic women. Obstet Gynecol 2006;108:77-82. 
34. Cnattingius S, Bergstrom R, Lipworth L, et al. Prepregnancy weight and the risk of adverse pregnancy outcomes. N Engl J Med 1998;338:147-52.

35. Cedergen MI. Maternal morbid obesity and the risk of adverse pregnancy outcome. Obstet Gynecol 2004;103:219-24.

36. Nohr EA, Bech BH, Davies MJ, et al. Prepregnancy obesity and fetal death: a study within the Danish national birth cohort. Obstet Gynecol 2005;106:250-9.

37. Dixit A, Girling JC. Obesity and pregnancy. J Obstet Gynaecol 2008;28:14-23.

38. Bertrand JM, Riley SP, Popkin J, et al. The long term pulmonary sequelae of prematurity: the role of familial airway hyperreactivity and the respiratory distress syndrome. $N$ Engl J Med 1985;312:742-5.

39. Riedel F, Achenbach U, Rieger CHL. Prematurity and maternal bronchial hyperresponsiveness, J Perinat Med 1989:17:151-5.

40. Milne F, Redman C, Walker J, et al. The preeclampsia community guidelines (PRECOG): how to screen for and detect onset of pre-eclampsia in the community. BMJ 2005;330:576-80.

41. Millar EA, Nally JE, Thomson NC. Angiotensin II potentiates methacholine-induced bronchoconstriction in human airway both in vitro and in vivo. Eur Respir $J$ 1995;8:1838-41.

42. Levin ER. Endothelins. N Eng/ J Med 1995;10:356-63.

43. Siddiqui S, Goodman N, McKenna S, et al. Preeclampsia is associated with airway

hyperresponsiveness. Br J Obstet Gynaecol 2008;115:520-2.

44. Schatz M, Zeiger RS, Harden K, et al. The safety of asthma and allergy medications during pregnancy. J Allergy Clin Immunol 1997;100:301-6.

45. Norjavaara E, de Verdier MG. Normal pregnancy outcomes in a population-based study including 2968 pregnant women exposed to budesonide. J Allergy Clin Immunol 2003;111:736-42.

46. Schatz M, Dombrowski MP, Wise, et al. The relationship of asthma medication use to perinatal outcome. J Allergy Clin Immunol 2004;113:1040-5.

47. Martel MJ, Rey E, Beauchesne MF, et al. Use of inhaled corticosteroids during pregnancy and risk of pregnancy-induced hypertension: nested case-control study. BMJ 2005;330:230-6.

48. Bakhireva LN, Jones KL, Schatz M, et al. Asthma medication use in pregnancy and fetal growth. Allergy Clin Immunol 2005;116:503-9.

49. Martel MJ, Rey E, Beauchesne MF, et al. Use of short-acting $\beta_{2}$-agonists during pregnancy and the risk of pregnancy-induced hypertension. J Allergy Clin Immunol 2007:119:576-82.

50. Bracken MB, Trichew EW, Belanger K, et al. Asthma symptoms, severity, and drug therapy: a prospective study of effects on 2205 pregnancies. Obstet Gynecol 2003;102:739-52.

51. Bakhirebva LN, Schatz M, Jones KL, et al. Asthma control during pregnancy and the risk of preterm delivery or impaired fetal growth. Ann Allergy Asthma Immunol 2008;101:137-43.

52. Schatz M, Zeiger RS, Hoffman CP, et al. Intrauterine growth is related to gestational pulmonary function in pregnant asthmatic women. Chest 1990;98:389-92.

53. Schatz M, Dombrowski MP, Wise R, et al Spirometry is related to perinatal outcomes in pregnant women with asthma. Am J Obstet Gynecol 2006;194:120-6.

54. Murphy VE, Clifton VL, Gibson PG. Asthma exacerbations during pregnancy: incidence and association with adverse pregnancy outcomes. Thorax 2006;61:169-76.

55. NAEPP Expert Panel Report. Managing asthma during pregnancy: recommendations for pharmacologic treatment-2004 update. J Allergy Clin Immunol 2005:115:34-46.

\section{The pulmonary protein C system: preventive or therapeutic target in acute lung injury?}

\section{Marcus J Schultz, ${ }^{1,2,3}$ Barry Dixon, ${ }^{4}$ Marcel Levi ${ }^{5}$}

Acute lung injury or its more severe form-acute respiratory distress syndrome (ARDS) - are common and important intensive care syndromes affecting many patients. Acute lung injury is characterised by damage to the alveolarcapillary membrane resulting in alveolar flooding, pulmonary inflammation and alveolar coagulopathy, and changes in surfactant properties with severe impairment of oxygenation and respiratory failure mandating mechanical ventilation. It is rarely present at the time of hospital admission but develops over a period of hours to days in subsets of patients with predisposing conditions such as trauma,

\footnotetext{
${ }^{1}$ Department of Intensive Care Medicine, Academic Medical Center, University of Amsterdam, Amsterdam, The Netherlands; ${ }^{2}$ Laboratory of Experimental Intensive Care and Anesthesiology (LEICA), Academic Medical Center, University of Amsterdam, Amsterdam, The Netherlands; ${ }^{3}$ HERMES Critical Care Group, Amsterdam, The Netherlands; ${ }^{4}$ Department of Intensive Care Medicine, St Vincent's Hospital, Melbourne, Australia; ${ }^{5}$ Department of Internal Medicine, Academic Medical Center, University of Amsterdam, Amsterdam, The Netherlands
}

Correspondence to: Dr M J Schultz, Department of Intensive Care Medicine, Academic Medical Center, Meibergdreef 9, 1105 AZ Amsterdam, The Netherlands; m.j.schultz@amc.uva.nl shock or sepsis, and accompanying interventions including mechanical ventilation and transfusion. ${ }^{1}$ Acute lung injury may therefore be viewed as a potentially preventable complication. Indeed, implementation of acute lung injury prevention strategies such as lung-protective mechanical ventilation using normal-sized tidal volumes and restrictive blood transfusion leads to a significant decrease in acute lung injury and mortality of mechanically ventilated patients. ${ }^{2}$ Pharmacotherapies targeting progression to acute lung injury may also benefit patients at risk of this complication. One such preventive strategy might be attenuation of pulmonary coagulopathy.

\section{COAGULOPATHY IN ACUTE LUNG INJURY}

Recent studies have shown that prominent changes in alveolar fibrin turnover are intrinsic to acute lung injury. ${ }^{3}$ The profile and extent of these changes vary with the severity of the injury. ${ }^{4}$ The mechanisms that contribute to pulmonary coagulopathy in acute lung injury are supposed to be similar to those found in the intravascular spaces in severe systemic inflammation (eg, sepsis or septic shock). ${ }^{5-7}$ Indeed, in acute lung injury, alveolar thrombin generation seems to be mediated, at least in part, by the tissue factor (TF)-factor VIIa (FVIIa) pathway, as the alveolar epithelium has been found to initiate TF-dependent intraalveolar coagulation in response to inflammation. ${ }^{8}$ Patients with ARDS show an increase in soluble TF, FVIIa and TFdependent factor $\mathrm{X}$ activation in bronchoalveolar lavage (BAL) fluid. ${ }^{56}$ Similarly, patients who develop ventilator-associated pneumonia have a rise in soluble TF and FVII in BAL fluid over time.? Furthermore, in ARDS, inhibition of the TF-FVIIa pathway completely abrogates intrapulmonary fibrin deposition. ${ }^{9}$ In association with enhanced fibrin production, fibrinolytic activity is depressed in BAL fluid of patients with acute lung injury or ARDS, ${ }^{4}$ related to raised levels of plasminogen activator inhibitor 1 (PAI-1), the main inhibitor of fibrinolysis. PAI- 1 is increased in acute lung injury and is probably secreted by lung epithelial cells, fibroblasts and endothelial cells. ${ }^{10}{ }^{11}$ Patients at risk of ventilator-associated pneumonia show similar changes in pulmonary fibrin breakdown. ${ }^{7}$ Although the lung has only a limited capacity to produce protein $\mathrm{C}$, activated protein $\mathrm{C}$ (APC) is present in BAL fluid. ${ }^{12}$ The protein $\mathrm{C}$ system is suppressed in patients with ventilator-associated pneumonia ${ }^{13}$ and acute lung injury or ARDS. ${ }^{14}$

\section{ANTICOAGULANT TREATMENT IN CRITICAL CARE PRACTICE}

Recombinant human activated protein $\mathrm{C}$ for severe sepsis and septic shock

Intravascular fibrin formation with sepsis is thought to perpetuate diffuse 